\title{
Tari Poang dan Tari Olang-olang Pertunjukan Ritual Masyarakat Sakai di Kabupaten Bengkalis, Riau
}

\author{
Asril $^{1}$, Novesar Jamarun ${ }^{2}$, Hamzah $^{3}$, Masnur Halilintar ${ }^{4}$, Trio Saputra ${ }^{5}$ \\ 1, 2,3 Institut Seni Indonesia Padangpanjang \\ ${ }^{4,5}$ Universitas Lancang Kuning Pekanbaru \\ asrilmuchtar2017@gmail.com
}

\begin{abstract}
Tari Poang merupakan tari ritual adat penyambutan tamu oleh masyarakat Sakai, khususnya Bathin Sobanga dari kelompok suku Bathin Solapan, Kabupaten Bengkalis. Tarian ini hanya ditampilkan dalam penyambutan tamu-tamu adat, pemerintahan, dan yang dianggap terhormat oleh masyarakat Sakai. Sementara tari Olang-olang merupakan tarian ritual masyarakat Sakai yang bersumber dari ritual pengobatan badike. Tari Olang-olang ditemui di berbagai kelompok bathin yang terdapat pada Bathin Solapan. Materi gerak tarian ini terinspirasi dari gerak-gerak elang terbang. Elang dijadikan sebagai hewan utama dalam kepercayaan masyarakat Sakai yang mampu terbang tinggi mengantarkan doa dan mantra mereka kepada Tuhan pada saat pengobatan. Penelitian ini bertujuan untuk membahas Tari Poang dan Tari Olang-olang yang menjadi tari pertunjukan ritual masyarakat Sakai pada kelompok suku Bathin Solapan di Kabupaten Bengkalis. Penelitian ini merupakan studi kasus pertunjukan ritual pengobatan pada masyarakat Sakai. Pengamatan terhadap peristiwa ritual dan pertunjukan tarian ini sangat penting dilakukan untuk mendapat data yang valid, terkait dengan bentuk pertunjukan, ekspresi, dan suasana ritual.
\end{abstract}

Keywords: Tari Poang, tari Olang-olang, pertunjukan ritual, masyarakat Sakai.

\section{Poang Dance and Olang-olang Dance: Ritual Performance Sakai Community in Bengkalis Regency, Riau}

Poang dance is the customary ritual dance of welcoming guests by Sakai people especially Bathin Sobanga of the tribal group of Bathin Solapan, Bengkalis district. This dance is only performed for welcoming customary guests, government, and figures respected by Sakai people. Meanwhile, Olang-Olang dance is the ritual dance of Sakai people sourced from the medicinal ritual of badike. Olang-Olang dance is found in various bathin groups found in Bathin Solapan. This dance movement material is inspired from the movements of flying eagle. Eagle is made as the main animal in Sakai people's belief that is able to fly high in order to deliver their pray and spells to the God at the time of medication. This research aims at discussing Poang dance and Olang-Olang dance that become the ritual dance of Sakai people in the tribal group of Bathin Solapan in Bengkalis district. This research is the case study of medicinal ritual performance in Sakai community. Observation toward these ritual event and dance performance is very important to be conducted in order to obtain valid data related to performance form, expression, and ritual atmosphere.

Keywords: Poang dance, Olang-olang dance, ritual performance, Sakai community.

Proses Review : 1 - 20 Mei 2020, Dinyatakan Lolos: 29 Mei 2020 


\section{PENDAHULUAN}

Masyarakat Sakai di Kabupaten Bengkalis dalam pandangan umum orang-orang di luar mereka cenderung apriori dengan menempatkan orang Sakai sebagai masyarakat pedalaman atau suku anak dalam. Orang-orang Sakai faktanya memang masih banyak yang tinggal di hutanhutan pedalaman Kecamatan Mandau, Bathin Solapan, dan Pinggir, Kabupaten Bengkalis. Mereka pada mulanya kelompok nomaden dengan menggarap hutan dan ladang serta membuat tempat tinggal berpindah-pindah dari suatu tempat ke tempat lain dalam hutan. Kurtubi menjelaskan bahwa ... orang-orang Sakai selalu hidup menyendiri di dalam hutan belantara "Batin Selapan" yang sukar dicapai oleh orang luar dan hanya dikunjungi oleh segelintir orang Melayu (Kurtubi, diakses 5 Agustus 2019). Mereka yang sulit ditemui, sehingga cenderung 'eksklusif' berinteraksi antar sesama dalam komunitas mereka saja. Berbagai adat, tradisi, keyakinan dan produk budaya lainnya yang mereka miliki menjadi pedoman dalam menjalankan aktivitas sehari-hari dalam komunitas mereka.

Akan tetapi, tidak semua orang Sakai adalah suku pedalaman. Saat ini banyak sekali orang-orang Sakai yang sangat maju dalam berbagai hal. Mereka berperan dalam berbagai aspek kebudayaan, seperti bidang ekonomi, politik, pendidikan, pelestarian dan pemajuan kebudayaan, berbagai posisi pimpinan dan staf dalam pemerintahan. Khusus dalam bidang pelestarian dan pemajuan kebudayaan, orang-orang Sakai juga memiliki kepedulian yang tinggi. Mereka memiliki desa adat yang disebut Desa Adat Sakai atau Desa Adat Suku Sakai yang terletak di Desa Kesumbo Ampai, Kecamatan Bathin Solapan, Kabupaten Bengkalis. Situs kompleks rumah adat didirikan di desa ini sebagai bukti konkret wadah mengartikulasikan aktivitas budaya, artefak (bangunan untuk aktivitas adat dan budaya, benda-benda pusaka), ritual dan aturan yang terkait dengan adat mereka. Kompleks ini sudah dibangun secara modern, sebagai wujud kemajuan yang dicapai pada budaya Sakai.

Orang Sakai yang masih tinggal di hutan dan orang-orang Sakai yang sudah maju, kemudian dikelompokkan pula secara dikotomis menjadi dua, yaitu kelompok Sakai Dalam (masih tinggal dalam hutan) dan Sakai Luar (yang sudah ke luar dari hutan dan sudah maju). Orang Sakai Luar tinggal desa-desa yang sudah maju dan di kota-kota, seperti Duri, Dumai, Pekanbaru, dan kota-kota lainnya. Mereka telah berinteraksi dengan berbagai suku dari daerah lain, seperti: Minang, Jawa, Batak, Banjar, Bugis, Sunda, dan lain sebagainya.

Orang-orang Sakai yang sudah maju, tidak ada bedanya dengan orang-orang lain dari Melayu, Minang, Batak, Jawa dan lain sebagainya. Kemajuan yang mereka alami berdampak pada budaya mereka. Sebagian besar masyarakat Sakai, khususnya yang tinggal di perkotaan sudah banyak meninggalkan budaya leluhur mereka. Misalnya tradisi pengobatan badike yang dilakukan melalui serangkaian ritual yang dipimpin oleh dukun, sudah banyak yang tidak melakukannya lagi. Namun sebagian lainnya dan orang-orang Sakai yang masih tinggal di pedalaman masih melakukan ritual pengobatan. Selain itu, dari aspek seni pertunjukan orang-orang Sakai masih memiliki tradisi ritual berupa tarian, yaitu tari Poang dan tari Olang-olang. Tari Poang merupakan salah satu tarian ritual adat masyarakat Sakai, khususnya dari komunitas Bathin Sobanga. Sementara tari Olang-olang menjadi identitas budaya dan seni masyarakat Sakai secara umum.

Tari Poang atau tari perang merupakan tari ritual adat penyambutan tamu oleh masyarakat Sakai, khususnya Bathin Sobanga dari kelompok suku Bathin Solapan, Kabupaten Bengkalis. Tarian ini hanya ditampilkan dalam penyambutan tamu-tamu adat, dari komunitas adat, pemerintahan, dan yang dianggap terhormat oleh masyarakat Sakai. Tari Poang tercipta dari cerita rakyat masyarakat Sakai, yaitu Putri Punai Onai yang mengisahkan 'perang saudara' yang terjadi antar sesama orang Sakai, sehingga gerak-gerak dan properti tari Poang bersumber dari silat dan benda-benda yang dipakai untuk perang, seperti tombak dan panah. Sementara tari Olang-olang merupakan tarian ritual masyarakat Sakai yang bersumber dari ritual pengobatan badike. Tari Olang-olang ditemui di berbagai kelompok bathin yang terdapat pada Bathin Solapan. Materi gerak tarian ini terinspirasi dari gerak-gerak elang terbang. Mengapa elang dijadikan inspirasi penciptaan tarian ini? Kemudian bagaimana orang-orang Sakai menyajikan kedua tarian ini dalam konteks ritual mereka?

\section{METODE PENELITIAN}

Penelitian ini merupakan studi kasus terhadap ritual dan pertunjukan masyarakat Sakai di Bengkalis, yaitu badike, tari Poang dan tari Olang-olang. Pengumpulan data dilakukan melalui studi literatur dan studi lapangan. Studi pustaka difokuskan mencari berbagai sumber-sumber tertulis, seperti artikel, hasil penelitian, dan buku yang dapat dijadikan data dan referensi untuk mendukung dan membahas permasalahan penelitian. Pengumpulan data lapangan difokuskan mengamati aktivitas dan perilaku masyarakat Sakai dalam konteks tradisi, ritual, adat istiadat seperti tarian Olang-olang dan ritual pengobatan. Tari dijadikan sebagai media mengekspresikan tujuan ritual, sementara ritual menjadi peristiwa untuk menyampaikan berbagai keinginan dan keluh kesah dalam kehidupan masyarakat Sakai. Data lapangan diperlukan untuk mendapatkan berbagai informasi, konsep yang berkaitan dengan budaya (ritual dan tarian) masyarakat Sakai. Data lapangan dikumpulkan secara langsung dalam bentuk data primer dan dilengkapi dengan data sekunder dari berbagai rekaman video dan foto yang terkait objek material penelitian. Untuk mendapatkan berbagai informasi, pengertian, tujuan, dan makna yang terkandung dalam ritual dan pertunjukan 
tari, maka dilakukan wawancara dengan sejumlah pelaku ritual, penari, para tokoh masyarakat Sakai, dan dari kalangan pemuda yang memiliki perhatian tinggi terhadap budaya mereka.

\section{ANALISIS DAN INTERPRETASI DATA}

Menurut pandangan Almaney dan Alwan seperti dikutip oleh Liliweri bahwa, setiap kebudayaan harus mencakup tiga kategori utama yang disebut sebagai the ingredient of culture, yaitu: (1) artefak (benda-benda), (2) konsep, mencakup keyakinan, sistem nilai, etika, dan makna umum kehidupan, (3) perilaku, seperti praktik dari konsep atau keyakinan (Liliweri, 2014: 9). Pandangan yang senada dengan ini disampaikan oleh Honigmann dan Koentjaraningrat yang membedakan tiga gejala kebudayaan, yaitu: ideas, activities, dan artifact. Dari ketiga gejala ini Koentjaraningrat menegaskan kebudayaan dalam wujudnya, yaitu: wujud kebudayaan sebagai suatu kompleks dari ide, gagasan, nilai, norma, peraturan dan sebagainya; wujud kebudayaan sebagai suatu kompleks aktivitas serta tindakan berpola dari manusia dalam masyarakat; wujud kebudayaan sebagai benda-benda hasil karya manusia (Koentjaraningrat, 2009: 150). Lebih lanjut dijelaskan oleh Koentjaraningrat bahwa, wujud kebudayaan dalam tataran kompleks ide/ideal bersifat abstrak, tidak dapat diraba, dan berada dalam kepala warga masyarakat tempat kebudayaan itu hidup, kecuali ketika ia dituliskan ada dalam manuskrip atau karangan warganya. Ide dan gagasan hidup bersama dalam suatu masyarakat dan memberi jiwa kepada masyarakat itu. Ide dan gagasan seperti ini disebut sistem budaya (cultural system) yang dapat dipadankan dalam Bahasa Indonesia menjadi adat atau adat istiadat. Wujud kebudayaan dalam kompleks aktivitas yang disebut sistem sosial (social system) terkait dengan berbagai aktivitas manusia dalam berinteraksi, berhubungan, bergaul menurut pola-pola tertentu berdasarkan adat dan perilaku. (Koetjaraningrat, 2009: 151; lihat juga Pujileksono, 2015). Orang-orang Sakai yang telah lama hidup dan menetap, memiliki sistem kebudayaan dan sistem sosial sendiri yang mereka anut dan jadikan acuan dalam kehidupan sehari-hari. Ketiga wujud kebudayaan di atas, dalam praktiknya antara satu dengan lainnya akan saling terkait. Kompleks aktivitas, berupa: perilaku, interaksi, dan praktik-praktik yang berwujud dalam bentuk ritual, permainan, berbagai seni yang masuk dalam sistem sosial, akan diatur oleh wujud budaya, yaitu kompleks ide dan gagasan, seperti adat, nilai, dan norma (sistem budaya) yang berlaku dalam komunitas Sakai. Dalam hal ini dibahas melalui ritual badike (pengobatan), pertunjukan tari Poang dan tari Olang-olang serta melalui bathin sebagai simpul masyarakat Sakai dalam bersosial.

\section{Bathin: Simpul Masyarakat Sakai}

Secara sosial dan budaya masyarakat Sakai terhimpun dalam kesatuan organiasasi adat yang dikenal dengan kesatuannya Bathin Tigo Boleh (bathin tiga belas). Masing-mas- ing bathin merupakan satu kelompok suku yang dipimpin oleh seorang kepala suku yang disebut bathin atau datuk. Menurut Kamus Besar Bahasa Indonesia, bathin artinya pengulu adat (KBBI, 2014: 147). Jadi, bathin memiliki pengertian sebagai satuan kelompok suku dan juga berarti pemimpin dari kelompok suku. Ketiga belas bathin itu, delapan kelompok bathin terdapat di Kabupaten Bengkalis, yang menyebar di Kecamatan Mandau, Kecamatan Pinggir, dan Kecamatan Bathin Solapan, sedangkan lima kelompok bathin lagi berada di Kecamatan Minas, Kabupaten Siak. Masyarakat Sakai dalam kekerabatan memakai sistem matrilineal. Misalnya, jabatan kepala suku atau Bathin dari mamak (paman) turun ke kemenakan laki-laki (anak laki-laki saudara perempuan bathin), bukan ke putranya. Masyarakat Sakai juga memiliki suku atau marga, misalnya Melayu Tuo, Melayu Besar, Melayu Panjang, Senuu, Bonai, dan Domo.

Ada beberapa versi yang menjelaskan tentang bathin sebagai suatu kelompok suku, bathin sebagai kawasan budaya, dan bathin sebagai gelar adat atau jabatan menurut adat oleh seseorang yang menjabat sebagai kepala suku. Pertama, pendapat dari tokoh masyarakat dan pemuda Sakai dari Bathin Sobanga, yaitu Syopian salah seorang masyarakat di Desa Kesumbo Ampai dan Rasyid, salah seorang tokoh pemuda dan penggiat kebudayaan di Bathin Sobanga. Menurut mereka, Bathin Solapan terdiri dari delapan bathin, yaitu: (1) Bathin Sobanga, (2) Bathin Bomban Patani, (3) Bathin Suthan Botuah, (4) Bathin Bumbung, (5) Bathin Botuah, (6) Bathin Majolelo, (7) Bathin Panaso, (8) Bathin Beringin. Adapun Bathin Limo terdiri dari: (1) Bathin Singo Majo, (2) Bathin Minas, (3) Bathin Belutu, (4) Bathin Tiopati, (5) Bathin Tonganau. Bathin Solapan dipimpin oleh seorang kepala bathin, Bathin Limo dipimpin pula oleh seorang kepala bathin. Semua bathin dipimpin oleh seorang bathin pucuk yang mengepalai seluruh bathin. Pada saat ini yang menjadi pimpinan seluruh bathin berasal dari Bathin Sobanga yang berada di Desa Kesumbo Ampai, Kecamatan Bathin Solapan (Wawancara, 6 November 2019 di Desa Kesumbo Ampai).

Versi kedua, ditulis oleh Kurtubi yang menyatakan bahwa dalam hal sosial dan kepemimpinan tradisional masyarakat Sakai menganut konsep "Sistem Perbatinan"-sejenis kepala suku atau penghulu dalam budaya Melayu. Perbatinan Sakai terdiri atas "Batin Selapan" dan " Batin Limo". Batin Selapan terdiri atas: (1) Batin Bomban Petani, (2) Batin Sebangar Sungai Jeneh, (3) Batin Betuah, (4) Batin Bumbung, (5) Batin Sembunai, (6) Batin Jalelo, (7) Batin Beringin, (8) Batin Bomban Seri Pauh. Adapun Batin Limo terdiri atas: (1) Batin Tengganau, (2) Batin Beromban Minas, (3) Batin Belitu, (4) Batin Singameraja, (5) Batin Meraso. Masing-masing kelompok batin mempunyai induk, yaitu Batin Selapan induknya adalah Batin Jalelo, Batin Limo induknya adalah Batin Tengganau. (Kurtubi, 2017). Kurtubi menulis kata bathin dengan batin dan solapan dengan selapan. 
Versi ketiga, berdasarkan data struktur kepemimpinan lembaga adat masyarakat Sakai Riau yang terdapat pada rumah adat Bathin Sobanga di Desa Kesumbo Ampai. Bathin Solapan/Lapan terdiri dari: (1) Bathin Pauh, (2) Bathin Pinggei, (3) Bathin Tongonong, (4) Bathin Somunai, (5) Bathin Lubuk, (6) Bathin Sebanga, (7) Bathin Senuun, (8) Manti Ijau, (9) Bathin Sotupag. Adapun Bathin Lima (limo) terdiri dari: (1) Bathin Kandih, (2) Bathin Bolutu, (3) Bathin Sam-sam, (4) Bathin Boingin, (5) Bathin Ponaso. Jabatan untuk Bathin Solapan dan Bathin Limo disebut Kepala Bathin. Kelompok Bathin Solapan dipimpin oleh Bathin Bomban Patani. Kelompok Bathin Limo dipimpin Bathin Bomban Mineh. Pimpinan untuk semua bathin (Bathin Solapan dan Bathin Limo) disebut Bathin Puncuk/pucuk, saat ini dijabat bathin (datuk) dari Bathin Sebanga Sungai Jeneh. Setiap pimpinan bathin dari bathin pucuk, kepala bathin, hingga kelompok bathin memiliki pembantu yang disebut tungkek. Tungkek merupakan pembantu bathin atau kepala suku, mulai dari tingkat kelompok bathin, kepala bathin, dan bathin pucuk. Bandingkan dengan panungkek di Minangkabau adalah pembantu pengulu adat sebagai pengganti di kemudian hari, atau bisa juga pengganti atau mewakili pengulu jika berhalangan datang dalam suatu acara (Payuang, 2015: 453). Setiap jabatan tungkek terdiri pula atas empat orang anggotanya. Para bathin, mulai dari pimpinan bathin, kepala bathin, hingga bathin puncuk/pucuk merupakan elit lokal masyarakat Sakai. Ada satu bidang tambahan pada kelompok Bathin Solapan versi struktur kepemimpinan Lembaga Adat Masyarakat Sakai, yaitu manti ijau. Manti ijau tampak tidak menunjukkan suatu kawasan kelompok suku, tetapi seperti jabatan dalam adat Sakai Bathin Solapan. Manti ijau juga memiliki tungkek dengan empat orang anggota yang membantunya dalam kegiatan adat dan diberi gelar adat ajong kayo.

Dari ketiga versi mengenai nama bathin dari kelompok Bathin Solapan dan Bathin Limo terdapat perbedaan, penyebutan nama bathin, dan penempatan bathin pada kedua kelompok bathin. Versi pertama menyebutkan nama-nama bathin pada kelompok Bathin Solapan dan kelompok Bathin Limo, tetapi ada nama bathin dari kelompok Bathin Limo terdapat pada Bathin Solapan. Begitu juga pada versi kedua, terjadi juga hal yang sama, jika dibandingkan dengan versi ketiga. Sementara pada versi ketiga ada nama-nama bathin yang tidak ditemukan pada versi pertama dan kedua. Perbandingannya dapat dilihat pada tabel 1 .

Perbedaan-perbedaan data dan informasi dari versi di atas, tampaknya diperlukan langkah berikutnya untuk mendata ulang kelompok bathin dengan nama kelompok dan keberadaannya dalam kelompok bathin, seperti Bathin Boingin. Kata boingin dalam dialek Sakai, dapat didekatkan dengan beringin dalam dialek Melayu. Jadi, Bathin Boingin berkemungkinan sama dengan Bathin Beringin. Jika itu sama, maka terjadi perbedaan penempatannya pada kelompok bathin, karena menurut versi 1 dan versi 2, Bathin Beringin ada dalam kelompok Bathin Solapan, sedangkan menurut versi 3, Bathin Boingin ada pada Bathin Limo.

\section{Ritual Pengobatan: Badike}

Masyarakat Sakai mewarisi ritual pengobatan dari nenek moyang mereka untuk mengobati berbagai jenis penyakit. Ritual pengobatan ini disebut badike. Ritual badike menggunakan jasa dukun yang disebut datuk sebagai orang yang memiliki kemampuan supranatural untuk mengobati orang yang sakit. Secara lebih luas, datuk adalah rujukan dalam berbagai jenis pengobatan tradisional, baik yang terkait dengan ritual hingga pengobatan sederhana tanpa ritual. Dukun memegang peranan penting sebagai mediator dalam menghubungkan dunia manusia dengan dunia gaib (roh-roh) pada berbagai ritual dan kegiatan adat.

Jenis penyakit yang diobati dengan cara badike adalah sakit yang disebabkan oleh gangguan roh halus, jin dan sejenisnya yang disebut tatogua. Tatogua dipahami sebagai sebuah gejala yang dialami oleh seseorang merasa sakit dalam berbagai hal di berbagai tempat di tubuhnya. Sakitnya disebabkan tatogua atau 'ditegur' oleh makhluk halus, dikarenakan seseorang mungkin saja karena tidak tahu dan tidak mengerti telah mengganggu, merusak, atau memasuki tempat tinggal para makhluk halus, sehingga ada di antara anggota kelompoknya yang tersakiti, yang mengakibatkan mereka marah. Bentuk-bentuk kemarahan makhluk halus bermacam-macam pula yang berwujud pada beberapa kategori penyakit dari yang sedang hingga yang berat. Gejala sakit seperti ini dipahami pula secara umum merupakan sakit yang tidak biasa, sehingga perlu diobati dengan ritual badike yang dipimpin oleh dukun. Menurut Syopian (50 tahun) salah seorang tokoh masyarakat adat Bathin Solapan di Desa Kesumbo Ampai menyatakan: "Cara pengobatan badike harus dilakukan dalam sebuah ritual dengan berbagai persiapan sebagai syarat yang harus disediakan oleh orang sakit dan yang dibawa sendiri oleh dukun. Pelaksanaannya harus dilakukan pada malam hari di rumah orang yang sakit dengan menghadirkan orang yang diobati itu di tempat pengobatan." (Syopian, wawancara, 7 November 2019 di Desa Kesumbo Ampai). Pelaksanaan ritual badike boleh disaksikan oleh orang lain, khususnya para keluarga dan tetangganya. Kami tim peneliti diberi izin pula menyaksikan ritual badike yang dilakukan pada 7 November 2019 di Desa Kesumbo Ampai, Kecamatan Bathin Solapan.

\section{Pelaksanaan Ritual Badike}

Ritual badike di masing-masing bathin dilakukan dengan cara yang berbeda-beda, namun memiliki banyak persamaan. Tim peneliti hanya dapat menyaksikan secara langsung ritual badike dalam konteks yang sesungguhnya pada keluarga Bathin Sobanga di Desa Kesumbo Ampai, Kecamatan Bathin Solapan, sedangkan badike di Koto Pait dilakukan tidak dalam konteks pengobatan (ha- 
Tabel 1. Perbandingan nama-nama bathin pada Bathin Solapan menurut tiga versi

\begin{tabular}{|c|c|c|c|c|}
\hline \multirow{2}{*}{ No. } & \multicolumn{3}{|c|}{ Nama-nama Bathin dalam Bathin Solapan } & \multirow{2}{*}{ Keterangan } \\
\hline & $\begin{array}{l}\text { Versi } 1 \text { (Syopian } \\
\text { dan Rasyid) }\end{array}$ & Versi 2 (Kurtubi) & $\begin{array}{c}\text { Versi } 3 \text { (Struktur lembaga } \\
\text { adat) }\end{array}$ & \\
\hline 1. & Bathin Sobanga & $\begin{array}{l}\text { Batin Sebangar Sungai } \\
\text { Jeneh }\end{array}$ & Bathin Sebanga & Perbedaan pada sebutan \\
\hline 2. & Bathin Bomban Patani & Batin Bomban Petani & - & Tidak ditemukan pada versi 3 \\
\hline 3. & Bathin Suthan Botuah & - & $\begin{array}{l}\text { Bathin Sotupag (Suthan } \\
\text { Botuah) }\end{array}$ & Tidak ditemukan pada versi 2 \\
\hline 4. & Bathin Bumbung & Batin Bumbung & Senuun (Bathin Bumbung) & Perbedaan sebutan \\
\hline 5. & Bathin Botuah & Batin Betuah & Lubuk (Bathin Botuah) & Perbedaan pada sebutan \\
\hline 6. & Bathin Majolelo & Batin Jalelo & Pinggei (Bathin Jolelo) & Perbedaan pada sebutan \\
\hline 7. & Bathin Panaso & - & - & $\begin{array}{l}\text { Tidak ditemukan pada versi } 2 \\
\text { dan } 3\end{array}$ \\
\hline 8. & Bathin Beringin & Batin Beringin & - & Tidak ditemukan pada versi 3 \\
\hline 9. & - & Batin Sembunai & Bathin Somunai & Tidak ditemukan pada versi 1 \\
\hline 10. & - & Batin Bomban Seri Pauh & $\begin{array}{l}\text { Bathin Pauh (Bathin Pak } \\
\text { Balik) }\end{array}$ & Tidak ditemukan pada versi 1 \\
\hline 11. & - & - & $\begin{array}{l}\text { Bathin Tongonong (Bathin } \\
\text { Tantaang Lidah) }\end{array}$ & $\begin{array}{l}\text { Tidak ditemukan pada versi } 1 \\
\text { dan } 2\end{array}$ \\
\hline
\end{tabular}

Tabel 2. Perbandingan nama-nama bathin pada Bathin Limo menurut tiga versi

\begin{tabular}{|c|c|c|c|c|}
\hline \multirow{2}{*}{ No. } & \multicolumn{3}{|c|}{ Nama-nama Bathin dalam Bathin Limo } & \multirow{2}{*}{ Keterangan } \\
\hline & $\begin{array}{l}\text { Versi } 1 \text { (Syopian } \\
\text { dan Rasyid) }\end{array}$ & Versi 2 (Kurtubi) & $\begin{array}{c}\text { Versi } 3 \text { (Struktur lembaga } \\
\text { adat) }\end{array}$ & \\
\hline 1. & Bathin Tonganau & Batin Tengganau & - & Tidak ditemukan pada versi 3 \\
\hline 2. & Bathin Minas & $\begin{array}{l}\text { Batin Beromban } \\
\text { Minas }\end{array}$ & - & Tidak ditemukan pada versi 3 \\
\hline 3. & Bathin Belutu & Batin Belitu & Bathin Bolutu & Perbedaan sebutan \\
\hline 4. & $\begin{array}{l}\text { Bathin Singo } \\
\text { Majo }\end{array}$ & Batin Singameraja & $\begin{array}{l}\text { Bathin Sam-sam (Bathin } \\
\text { Singgo Majo) }\end{array}$ & Perbedaan sebutan \\
\hline 5. & Bathin Tiopati & Batin Meraso & Bathin Ponaso & $\begin{array}{l}\text { Versi } 1 \text { berbeda, versi } 2 \text { dan } 3 \text { perbedaan } \\
\text { sebutan }\end{array}$ \\
\hline 6. & - & - & Bathin Kandih & Tidak ditemukan pada versi 1 dan 2 \\
\hline 7. & - & - & Bathin Boingin & $\begin{array}{l}\text { Tidak ditemukan pada versi } 1 \text { dan 2, kec- } \\
\text { uali disebutkan pada Bathin Solapan, mirip } \\
\text { dengan Bathin Beringin }\end{array}$ \\
\hline
\end{tabular}




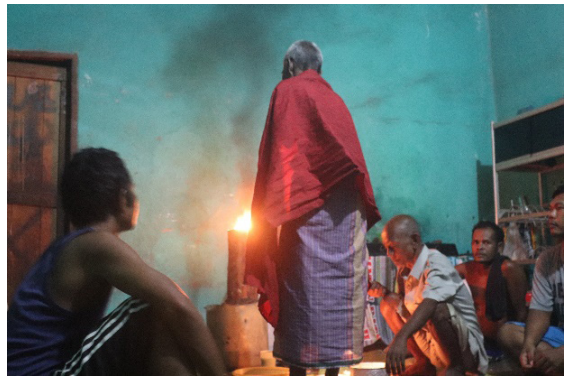

Gambar 1. Muhammad, dukun dari Bathin Sobanga menggunakan kain merah sebagai salah satu persyaratan ritual badike

(Foto: Asril Muchtar, 2019)

nya contohnya saja) sehingga, berbagai persyaratan yang terkait dengan pengobatan tidak dihadirkan sepenuhnya. Namun, dukun sebagai pemimpin ritual pada bagian-bagian tertentu dari 'ritual' dilakukan dengan sangat serius, sebagaimana pengobatan yang sesungguhnya. Misalnya, ketika dukun membaca mantra yang ditujukan kepada para leluhurnya, ia dapat 'berkomunikasi' secara batin melalui kemampuan supranaturalnya.

Ritual badike dipimpin oleh seorang dukun dan dibantu oleh beberapa orang untuk menyiapkan berbagai perlengkapan ritual dan pada saat ritual berlangsung termasuk pemusik odok atau bebano (alat musik perkusi bermuka satu) yang berfungsi untuk mengiringi dukun dalam membangun suasana ritual. Para pembantu dukun harus cermat, tanggap, dan paham dengan apa yang dilakukan oleh dukun serta kondisi dukun pada saat melakukan gerakan-gerakan yang menguras tenaganya, sehingga ia bisa saja terjatuh karena kelelahan. Gerak-gerak yang dilakukan oleh dukun sebagai wujud menggambarkan sedang terjadinya komunikasi dengan roh atau makhluk halus.

Sebelum ritual badike dimulai, semua persyaratan pengobatan dan unsur pendukung lainnya sudah harus tersedia di tempat pengobatan, termasuk menghadirkan si sakit. Setelah semua persyaratan lengkap, dukun akan menyampaikan kepada semua yang hadir dalam ruang pengobatan tanpa kecuali, yaitu: hal-hal yang berupa tulisan-tulisan atau doa dalam bentuk islami yang berada dalam tas, dompet, kantong, dan kitab suci (Al-Quran), serta jenis kitab lainnya yang berkaitan dengan Islam, termasuk hewan seperti kucing harus dikeluarkan dari areal pengobatan. Teks dan doa dari unsur Islam serta kucing atau hewan lainnya akan mengganggu proses ritual, karena jin atau makhluk halus tidak mau datang atau berkomunikasi dengan dukun, jika benda-benda tersebut ada dalam ruangan. Komunikasi dengan makhluk halus itu dilakukan dengan beberapa persyaratan pula, misalnya membakar kemenyan, beras botiah, ramuan obat, membuat perapian dengan bahan bakar damar dan sejumlah peralatan yang disediakan sendiri oleh dukun. Dukun dengan pembantunya menyalakan api, membakar botiah, menebar botiah di ruangan pengobatan, menyalakan lilin, dan meramu semua syarat-

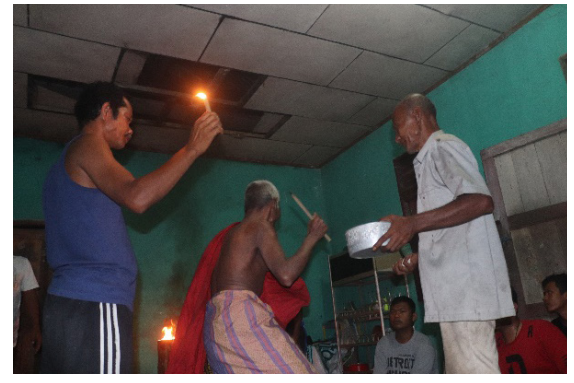

Gambar 2. Lilin yang digunakan oleh Muhammad saat bergerak padam, sementara para pembantunya siap pula memberikan lilin atau api untuk menghidupkan lilin Muhammad.

(foto: Asril Muchtar, 2019)

syarat pengobatan. Dukun menggunakan kain merah atau kain putih untuk menutupi punggungnya, selanjutnya merapalkan mantra, odok atau bebano dibunyikan untuk membangun suasana ritual. Mantra yang dirapalkan oleh dukun sangat sulit dipahami dan dimengerti kata-katanya. Mantra yang diucapkan bersifat rahasia, sangat sacral, dan memiliki unsur magis, sehingga dukun tidak bersedia mengulangi mengucapkannya di luar konteks ritual badike.

Setelah merapalkan mantra, dukun berdiri dan bergerak dalam ruang areal pengobatan yang berukuran sekitar 3 X 4 meter saja. Gerak-gerak yang dilakukan oleh dukun tampaknya bersifat improvisasi, tidak memiliki pola gerak yang jelas. Menurut Muhammad yang menjadi dukun dalam ritual badike di Bathin Sobanga mengatakan: "Gerak-gerak yang ia lakukan kadang-kadang muncul pada saat ritual pengobatan itu saja, setelah itu ia bisa lupa. Ia tidak memiliki pengalaman menjadi penari dan bersilat yang bisa dijadikan rujukan gerak, atau berorientasi pada gerak-gerak hewan seperti harimau, elang, kera, dan sebagainya." Gerak-gerak yang dilakukan oleh dukun menggambarkan sedang terjadi komunikasi dengan para jin atau makhluk halus yang menghinggapi si sakit, sehingga gerak-gerak yang muncul merupakan refleksi dukun terhadap 'dialog' dia dengan makhluk halus itu. Namun gerak-gerak yang dilakukan oleh Muhammad memiliki tenaga, dinami$\mathrm{ka}$, dan ruang gerak yang lebar karena menggunakan kain yang kedua ujung dipegang arah ke depan. Intensitas gerak yang dilakukan oleh Muhammad sangat komunikatif dengan tempo dan ritme pukulan odok. Contoh Muhamad saat melakukan ritual badike pada Gambar 1 dan 2 .

Durasi dukun bergerak tidak bisa ditentukan lamanya. Ini sangat bergantung pada komunikasi yang dilakukan oleh dukun dengan makhluk halus yang mengganggu orang yang sakit. Bergerak menjadi bagian proses ritual badike yang sangat berpengaruh kepada orang yang diobati. Menurut Muhammad, lamanya ia bergerak bisa saja berlangsung hingga tengah malam, tergantung dari berat dan ringannya penyakit yang diderita oleh si sakit. Makin berat penyakit yang diderita oleh si sakit, maka komunikasi dengan makhluk halus juga akan menjadi lama, sehingga gerak yang dilakukan pun menjadi lama pula. Ini member- 


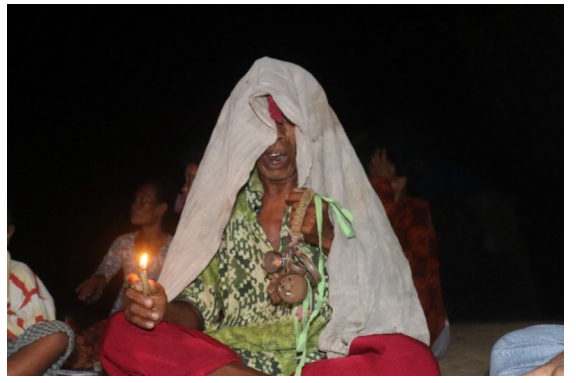

Gambar 3. Rim (70 tahun) dukun dari Koto Pait menggunakan kain putih sebagai salah satu persyaratan ritual badike

(Foto: Asril Muchtar, 2019)

ikan gambaran, seolah-olah terjadi tawar-menawar antara dukun dengan makhluk halus. Orang Sakai sangat percaya, bahwa dukun adalah orang yang berperan sebagai mediator antara orang yang sakit dengan makhluk halus yang mengganggu si sakit. Berbeda halnya dengan badike yang dilakukan di Koto Pait; Pak Rim, dukun yang memimpin ritual tidak melakukan gerak sebagaimana yang dilakukan oleh dukun di Desa Kesumbo Ampai. Gerak-gerak atau mereka sebut menari dilakukan oleh seorang perempuan (anak dukun) menggunakan kain panjang sebagai properti.

\section{Tari Poang}

Tari Poang (perang) adalah tari tradisi peperangan masyarakat Sakai sebagai tarian adat. Tarian ini hanya ditampilkan dalam ritual adat, seperti penyambutan tamu-tamu adat yang berasal dari berbagai daerah dan tamu dari kalangan pemerintah. Tari Poang ditarikan oleh laki-laki dewasa dengan jumlah ganjil. Penari akan menempati posisi dua berbaris dan satu orang berada di tengah antara kedua baris itu. Jumlah penari pada kedua baris itu harus genap, masing-masing baris bisa berjumlah dari 5 hingga 10 orang penari. Satu orang penari disebut pemanah.

Tari Poang terispirasi dari legenda Putri Punai Onai. Putri Punai Onai adalah seorang ratu yang memimpin suatu negeri yang aman dan damai, tetapi memiliki prajurit yang banyak. Sementara di daerah lain ada pula seorang raja yang bernama Potugal Bosi (nama ini berasal dari orang yang menugal dengan besi). Putri Punai Onai dan Raja Potugal Bosi sama-sama orang Sakai, tetapi Raja Potugal Bosi adalah raja yang keras, kejam, dan ingin menguasai semua daerah kerajaan-kerajaan yang lain termasuk daerah kekuasaan Putri Punai Onai. Sikap dari Raja Potugal Bosi menimbulkan peperangan antara dia dengan Putri Punai Onai.

Tari Poang terdiri dari lima struktur, yaitu: gondang poang, kumbang, panto, lancang kocik, dan olang-olang. Gondang poang adalah gerak-gerak yang berasal dari moncak (silat/silek), semua penari melakukan gerak moncak; kumbang adalah gerak berputar; panto, yaitu melakukan gerak berbaris kembali sambil memukul panto, sejenis properti yang terbuat dari papan/kayu yang bisa dibunyikan oleh semua penari dan sebagai tanda para tamu disilakan me-

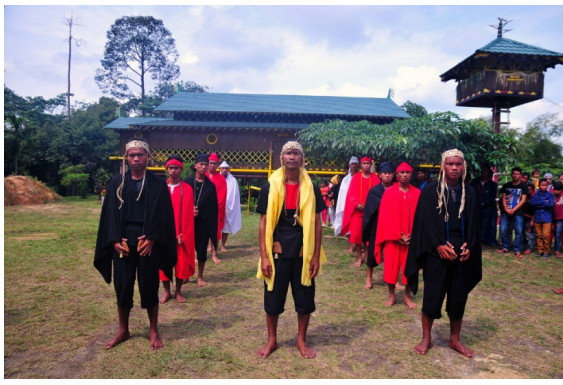

Gambar 4. Para penari tari Poang dengan busana warna hitam, merah, kuning, dan putih yang sudah dibuat dari bahan kain (Sumber: https://gambarbagus.com, diunduh 9 Desember 2019)

masuki rumah adat atau ruang tertentu; lancang kocik adalah gerak yang dilakukan oleh semua penari membentuk angka delapan; olang-olang adalah gerak memanah yang dilakukan oleh penari/pemanah yang memanah satu per satu dari semua penari hingga habis, dan selesai pula pertunjukan tari Poang. Durasi pertunjukan tari ini berkisar antara 20-25 menit.

Busana yang digunakan berwarna hitam, merah, putih, dan kuning dengan posisi selang-seling mulai dari depan, yaitu hitam, merah, hitam, merah, dan putih di bagian belakang, sedangkan untuk penari di tengah-tengah menggunakan busana warna hitam dan kain kuning sebagai pemanah. Penari di depan berbusana hitam disebut kepala. Busana dengan warna seperti ini merupakan hasil pembaruan menggunakan kain/tekstil pabrikan, namun tetap mengacu pada filosofi warna dalam konteks adat dan kehidupan yang digunakan oleh masyarakat Sakai. Selain busana berupa baju dan celana, para penari juga menggunakan atribut berwarna kuning muda atau krem bisa juga hitam yang disebut deta yang diikatkan di kepala, dan di sisi-sisinya ada jalinan panjang menjuntai ke depan. Pada masa lalu bahan busana penari terbuat dari kulit kayu yang diolah seperti lembaran kain, kemudian dibentuk menjadi baju dan celana. Berikut ini contoh busana yang digunakan oleh para penari tari Poang pada masa sekarang (Gambar 4) dan busana masa lalu yang menggunakan kulit kayu (Gambar 5).

Alat musik yang digunakan untuk mengiringi tari Poang adalah odok, gondang panjang, dan gambang. Odok dan gondang pajang berfungsi untuk mengatur tempo dan memainkan pola-pola ritme, sedangkan gambang berfungsi memainkan melodi. Setiap bagian atau struktur tari Poang yang diiringi, pola ritme odok dan gondang panjang berbeda, begitu juga dengan melodi gambang. Pada bagian olang-olang, tempo musik cepat, menggambarkan peperangan sudah usai. Alat musik yang digunakan dapat saja berbeda antara Bathin yang satu dengan yang lainnya. Salah satu alat musik yang sangat penting dan bersifat sakral pada Bathin Solapan adalah gambang. Gambang tidak dimiliki oleh bathin yang lain dalam mengiringi tari Poang. 


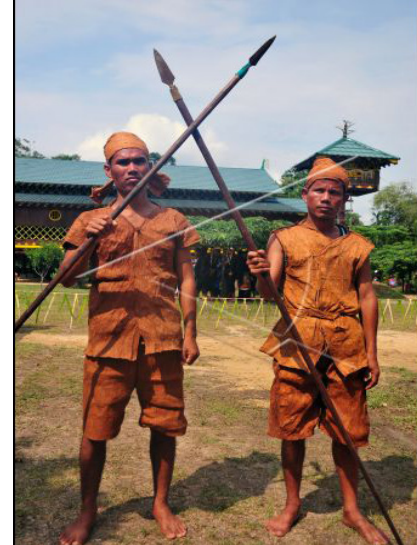

Gambar 5. Busana penari yang berasal dari bahan kulit kayu (Sumber: https://gambarbagus.com, diakses 9 Desember 2019)

Setiap pertunjukan tari Poang, harus dilakukan berbagai persiapan, seperti latihan memantapkan tari, membuat tapung tawar, dan lain sebagainya. Tapung tawar adalah suatu ritual menyapukan bunga yang terdiri dari tujuh macam yang diikat kemudian disapukan ke setiap penjuru alam dan mengasapi para penari. Tujuannya adalah meminta semah (izin) kepada ninik-ninik (para tetua adat), makhluk halus dan lainnya agar lokasi tempat menari aman dari berbagai gangguan dari apa dan siapa saja. Cara yang dilakukan oleh para penari Tari Poang ini adalah untuk membangun suasana ritual agar lebih meresap pada diri mereka dan kesakralan tarian bisa mereka rasakan. Mereka ingin membangun suasana liminal dan larut dalam pertunjukan, seperti yang dikatakan oleh Turner, bahwa untuk membangun suasana flow (hanyut, larut) dan liminal diperlukan kekhusukan dengan menghayati ritual dan pertunjukan yang dilakoni (Turner, 1982).

Aktivitas yang dilakukan oleh para penari tari Poang sebagai persiapan menjelang pertunjukan menjadi bagian dari ritual. Kemudian keesokan harinya dilanjutkan dengan pertunjukan dan setelah selesai pertunjukan mereka membereskan kembali arena pertunjukan dan semua perlengkapan yang terkait dengan pertunjukan. Semua ini merupakan prinsip dasar dari pertunjukan yang disebut deep structur of performance oleh Schechner. Persiapan tidak hanya terfokus pada aktivitas yang berbau ritual saja, tetapi juga materi tarinya. Schechner (2013) menekankan bahwa dalam setiap pertunjukan persiapan berupa latihan terhadap materi pertunjukan sangat penting, karena setiap penyaji akan menyajikan perilaku yang telah dilatihkan dan ditingkatkan dari perilaku biasa dalam keseharian. Schechner menyebutkan cara ini dengan restored behavior.

\section{Tari Olang-olang}

Tari Olang-olang secara umum dimiliki oleh setiap Bathin yang ada di Kabupaten Bengkalis (Bathin Solapan) dan Kabupten Siak (Bathin Limo) sebagai tari tradisi. Keberadaan tari ini sangat terkait dengan tradisi ritual badike. Menurut Khairul Layali, masyarakat Sakai yang ada di
Minas, Kabupaten Siak dari kelompok Sakai Bathin Limo, bahwa tari Olang-olang merupakan tari yang digunakan untuk mengiringi pengobatan yang dilakukan oleh orang Sakai dalam menyembuhkan penyakit. Tari Olang-olang sarat dengan dengan dunia gaib. Orang-orang Sakai percaya gangguan roh halus hanya dapat disembuhkan oleh dukun atau bomo. Bomo melalui roh soli yang dipercayai sebagai roh nenek moyang mereka dan diakui sebagai seorang bomo. Olang-olang mempunyai makna burung terbang (elang) yang menggambarkan simbolisasi komunikasi antara bomo dengan roh soli dalam proses penyembuhan orang yang sakit. (Layali, 2014: 94, 98). Bomo adalah sebutan lain dari dukun yang sama pengertiannya dengan datuk pada Sakai Bathin Solapan.

Akan tetapi, konteks badike, tampak tidak selalu menghadirkan tari Olang-olang. Misalnya, ritual badike yang dilakukan di kawasan Bathin Sobanga pada 7 November 2019 yang dipimpin oleh Muhammad, tari Olang-olang tidak ditampilkan. Muhammad yang sekaligus 'menari' pada saat ritual itu, secara tegas mengatakan bahwa ia tidak menarikan tari Olang-olang, bahkan ia juga menyatakan bahwa gerak-gerak yang ia tampilkan pun tidak bersumber dari peniruan gerak elang. Namun, menurut penuturan Rasyid dan Syopian, di Bathin Sobanga diakui ada tari Olang-olang, tetapi ditampilkan pada ritual adat. (Wawancara, 6 November 2019 di Desa Kesumbo Ampai). Sementara tari Olang-olang di Koto Pait juga digunakan untuk ritual pengobatan. Pada saat dukun melakukan ritual badike, ada orang lain yang berperan sebagai penari, yaitu seorang perempuan, anak dari dukun yang memimpin ritual. Penari dan dukun menyatakan bahwa tari yang ditarikan saat ritual itu adalah tari Olang-olang. Dukun juga berkomunikasi batin dengan roh leluhurnya.

Pertunjukan tari olang-olang dari Bathin Beringin Koto Pait dilakukan oleh seorang perempuan bernama Dewi. Dewi bergerak dengan lincah menirukan gerak elang. Kadang-kadang ia bergerak meninggi, merendah, jongkok, dan mengepak-ngepakkan kain seperti menirukan sayap elang sedang terbang dan gerak elang hendak turun menangkap mangsanya. Pola gerak dan strukturnya tampak spontan atau fleksibel; gerak-gerak yang dilakukan seperti merespons ritme bebano. Ini sangat bisa dimaklumi, karena berada dalam konteks ritual, sehingga gerak-gerak yang dilakukan bisa saja pola dan strukturnya fleksibel. Pada saat Dewi menari, muncul seorang anak perempuan yang masih kecil menggunakan kain turut pula bergerak menirukan gerak-gerak yang ditarikan oleh Dewi. Anak perempuan itu berinisiatif sendiri tampil menari bersama Dewi (bibinya). Ini menunjukkan bahwa ada regenerasi penari dalam kelompok orang Sakai di pedalaman Koto Pait. Durasi pertunjukan berlangsung sekitar 5-7 menit. Menurut Dewi: "Gerak-gerak yang ia lakukan seperti meniru gerak burung. Ia membenarkan bahwa gerak-gerak yang ia lakukan itu bersumber dan terinspirasi dari gerak elang, sehingga tarian itu diberi nama 


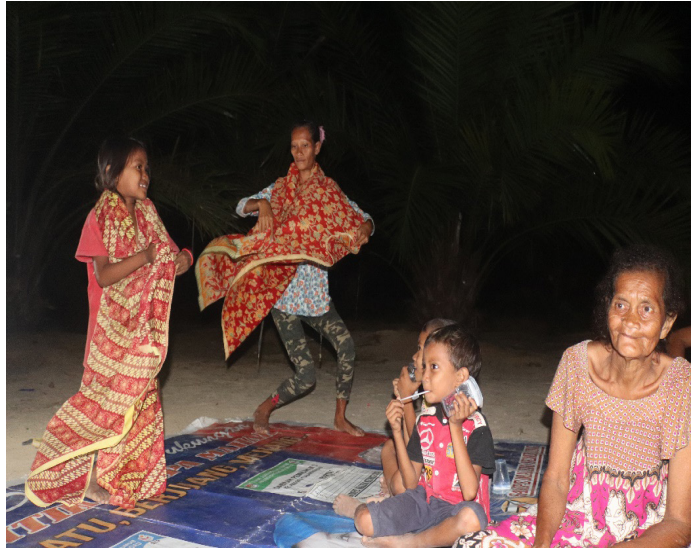

Gambar 6. Penari sedang melakukan gerak tari Olang-olang (Foto: Asril Muchtar, 2019).

tari Olang-olang (elang).” (Dewi, wawancara 5 November 2019 di Koto Pait).

Dewi bergerak dengan ringan dan lincah merepresentasikan dan menginterpretasikan perilaku elang saat terbang. Situasi yang dialami dan ekspresi yang dihadirkan oleh penari, tampak bahwa penari berada dalam suasana flow, hanyut, larut menghayati peran yang ia tarikan. Sebagaimana yang dinyatakan oleh Csikszentmihalyi, bahwa dalam tubuh pelaku (penari) telah terjadi peleburan laku/tindakan dengan kesadarannya. Ia menyadari apa yang sedang dilakukan, tetapi tidak menyadari bahwa ia sadar (Turner, 1982: 56; lihat juga Asril, 2016: 290-291). Peleburan tindakan penari dengan kasadarannya sangat bergantung pada kemampuan dan kedalaman penghayatan penari terhadap ritual dan mitos elang yang menjadi rujukan imajinasinya. Penari tampak telah membangun imajinasi dan penghayatan yang kuat, sehingga ia bisa menari dengan lincah, ringan, dan fleksibel laksana elang terbang. Menurut Layali, penari Olang-olang saat menari merasakan tubuhnya ringan dan bergerak halus dan leluasa. Perasaan terasa nyaman, pikiran menjadi kosong, pemandangan terasa seperti dalam dunia sendiri, seperti rasa mabuk, sehingga gerakan-gerakan mengalir secara spontan seperti burung elang yang sedang terbang bebas dan lincah di angkasa (Layali, 2014: 98-99).

Orang Sakai memercayai 'Rajo Olang-olang' (dalam dialek Sakai) atau raja elang adalah burung yang mampu terbang ke langit. Dukun akan 'berkomunikasi' dengan elang sebagai penyampai pesan kepada Tuhan. Olang-olang adalah burung elang yang disimbolkan sebagai soli atau hantu yang bersedia memberikan bantuan untuk mendapatkan petunjuk dari dunia gaib yang bermanfaat untuk dunia nyata (Layali, 2014: 102). Dengan kepercayaan demikian, makanya tari Olang-olang dimiliki oleh setiap kelompok Bathin. Meskipun, masyarakat Sakai umumnya beragama Islam, namun dalam beberapa ritual tertentu terjadi sinkretik dengan kepercayaan lama.

Sistem pengelompokkan dari semua bathin yang ada, pelaksanaan ritual badike, pertunjukan tari Poang, dan tari Olang-olang merupakan wujud budaya masyarakat Sakai dalam bentuk konsep yang mencakup keyakinan, sistem nilai, etika, dan praktik dari konsep itu, sebagaimana yang dinyatakan Almaney dan Alwan dalam the ingredient of culture. Begitu juga dengan insteraksi, berhubungan, bergaul yang terjadi antar sesama orang Sakai, sebagaimana yang dinyatakan oleh Koentjaraningrat bertolak dari ide dan gagasan hidup bersama dalam suatu masyarakat dan memberi jiwa kepada masyarakat itu. Ide dan gagasan seperti ini disebut sistem budaya (cultural system).

\section{SIMPULAN}

Ritual Badike dilakukan oleh orang-orang Sakai yang masih mempercayai sakit yang disebabkan oleh gangguan makhluk halus atau makhluk gaib yang disebut tatogua. Sakit karena tatogua hanya bisa disembuhkan dengan dukun melalui suatu ritual badike. Badike dilaksanakan dengan berbagai persyaratan yang dilakukan pada malam hari di rumah si sakit. Badike tidak hanya ritual pengobatan semata, tetapi juga menghadirkan pertunjukan tarian yang disebut tari Olang-olang. Tari Olang-olang menjadi bagian penting dalam ritual badike di kelompok Bathin tertentu dan ada juga menjadi tarian terpisah pada bathin yang lain. Penyajian tari Olang-olang sebagai gambaran 'komunikasi' yang terjadi antara dukun dengan makhluk gaib yang mengganggu si sakit atau berkomunikasi dengan roh para leluhur untuk meminta bantuannya agar bisa menyembuhkan orang yang sakit. Tari Olang-olang terinspirasi dari gerak-gerak elang terbang. Elang dianggap makhluk yang mampu terbang tinggi dan mampu membawa pesan kepada Tuhan yang maha tinggi. Tari Poang merupakan tari tradisi ritual adat yang difungsikan untuk menyambut tamu-tamu dari kalangan adat dan pemerintahan. Tari ini adalah tari perang (Poang) yang terinspirasi dari legenda Putri Punai Onai, seorang putri (raja) yang baik, negerinya yang aman, dan damai serta memiliki parajurit yang tangguh. Ia diserang oleh raja Potugal Bosi yang kejam dan haus kekuasaan, tetapi bisa dikalahkan oleh prajurit Putri Punai Onai. Tari Olang-olang dan tari Poang merupakan tarian ritual dan menjadi kebanggaan masyarakat Sakai.

\section{DAFTAR RUJUKAN}

Asril. (2016). "Tabuik: Pertunjukan Budaya Hibrid Masyarakat Kota Pariaman, Sumatra Barat". Disertasi Doktor Program Pascasarjana ISI Yogyakarta.

Bapayuang, Yos magek. (2015). Kamus Baso Minang. Jakarta: Mutiara Sumber Ilmu.

Departemen Pendidikan Nasional. (2014). Kamus Besar Bahasa Indonesia. Edisi Keempat. Jakarta: Gramedia Pustaka Utama. 
Haviland, William A. (1985). Antropologi. Jilid 2 edisi keempat. Jakarta: Erlangga.

Layali, Khairul., Rosta Minawati, dan Yusfil. (Juli, 2014). "Tari Olang-olang dalam Ritual Pengobatan Suku Sakai di Kecamatan Minas, Kabupaten Siak," dalam Bercadik: Jurnal Pengkajian dan Penciptaan Seni. Vol. 2 No. 1. Pascasarjana ISI Padangpanjang.

Layali, Khairul. (2015). “Tari Olang-olang sebagai seni pertunjukan pada masyarakat Suku Sakai Kecamatan Minas, Kabupaten Siak". Tesis S2 Program Pascasarjana ISI Padangpanjang.

Liliweri, Alo. (2014). Pengantar Studi Kebudayaan. Bandung: Nusa Media

Koentjaraningrat. (2009). Pengantar Ilmu Antropologi. Jakarta: Rineka Cipta.

Pujileksono, Sugeng. (2015). Pengantar Antropologi: Memahami Realitas Sosial Budaya. Malang: Intrans Publishing.

Rahman, Elmustian, et al. (2017). Ensiklopedia Budaya Bengkalis, Jilid 1. Bengkalis: Dinas Pariwisata, Kebudayaan, Kepemudaan, dan Olah Raga Kabupaten Bengkalis.

Rahman, Elmustian, et al. 2017. Ensiklopedia Budaya Bengkalis, Jilid 2. Bengkalis: Dinas Pariwisata, Kebudayaan, Kepemudaan, dan Olah Raga Kabupaten Bengkalis.

Schechner, Richard. (2013). Performance Studies: an Introduction. London: Routledge.

Turner, Victor. (1982). From Ritual to Theatre: The Human Seriousness. New York: PAJ Publication.

\section{Webtografi:}

Kurtubi, Dodi Ahmad. (2017). "Mengenal Suku-suku Asli (Komunitas Adat Terpencil) di Provinsi Riau." Diunduh 25 Juli 2019 dari dinsos.riau.go.id.

Melancong ke "benteng” budaya Suku Sakai (2016). Diunduh 25 Juli 2019 dari www.antaranews.com.

Diunduh 9 Desember 2019 dari https://gambarbagus.com.

\section{Daftar Informan:}

Abdul Rasyid, (28 tahun), tokoh pemuda dan penggiat kebudayaan Sakai dari Bathin Sobanga, wawancara 7 November 2019 Rumah Adat Sakai Desa Kesumbo Ampai, Kecamatan Bathin Sobanga, Kabupaten Bengkalis, Riau.
Dewi, (40 tahun), penari tari Olang-olang dari Bathin Beringin, wawancara 5 November 2019 di Desa Koto Pait.

Muhammad, (70 tahun), dukun dari Bathin Sobanga, wawancara 6 November 2019 di Desa Kesumbo Ampai, Kecamatan Bathin Sobanga, Kabupaten Bengkalis, Riau.

Rim, (71 tahun), dukun dari Bathin Beringin, wawancara 5 November 2019 di Desa Koto Pait.

Syopian, (50 tahun), pemuka masyarakat Sakai Bathin Sobanga Desa Kesumbo Ampai, wawancara di Desa Kesumbo Ampai, Kecamatan Bathin Sobanga, Kabupaten Bengkalis, Riau. 